Article

\title{
Trend dynamics of GRACE terrestrial water storage in the Nile River Basin
}

\author{
Emad Hasan ${ }^{1,2,3, *}$, Aondover Tarhule ${ }^{1}$ \\ 1 Department of Geography, State University of New York, SUNY at Binghamton, Binghamton 13902, NY, \\ USA; atarhule@binghamton.edu \\ 2 Hydrometeorology and Remote Sensing (HyDROS) Laboratory, Advanced Radar Research Center \\ (ARRC), University of Oklahoma, Norman, 73019, OK, USA \\ 3 Geology Department, Faculty of Science, Damietta University, New Damietta 34518, Egypt. \\ * Correspondence: emad.hasan@ou.edu
}

\begin{abstract}
GRACE-derived Terrestrial Water Storage Anomalies (TWSA) continue to be used in an expanding array of studies to analyze numerous processes and phenomena related to terrestrial water storage dynamics, including groundwater depletions, lake storage variations, snow, and glacial mass changes, as well as floods, droughts, among others. So far, however, few studies have investigated how the factors that affect total water storage (e.g., precipitation, runoff, soil moisture, evapotranspiration) interact and combine over space and time to produce the mass variations that GRACE detects. This paper is an attempt to fill that gap and stimulate needed research in this area. Using the Nile River Basin as case study, it explicitly analyzes nine hydroclimatic and anthropogenic processes, as well as their relationship to TWS in different climatic zones in the Nile River Basin. The analytic method employed the trends in both the dependent and independent variables applying two geographically multiple regression (GMR) approaches: (i) an unweighted or ordinary least square regression (OLS) model in which the contributions of all variables to TWS variability are deemed equal at all locations; and (ii) a geographically weighted regression (GWR) which assigns a weight to each variable at different locations based on the occurrence of trend clusters, determined by Moran's cluster index. In both cases, model efficacy was investigated using standard goodness of fit diagnostics. The OLS showed that trends in five variables (i.e., precipitation, runoff, surface water soil moisture, and population density) significantly $(\mathrm{p}<0.0001)$ explain the trends in TWSA for the basin at large. However, the models R2 value is only 0.14 . In contrast, the GWR produced R2 values ranging between 0.40 and 0.89 , with an average of 0.86 and normally distributed standard residuals. The models retained in the GWR differ by climatic zone. The results showed that all nine variables contribute significantly to the trend in TWS in the Tropical region; population density is an important contributor to TWSA variability in all zones; ET and Population density are the only significant variables in the semiarid zone. This type of information is critical for developing robust statistical models for reconstructing time series of proxy GRACE anomalies that predate the launch of the GRACE mission and for gap-filling between GRACE and GRACE-FO.
\end{abstract}

Keywords: GRACE TWS, GRACE-FO, Nile River Basin, Spatial autocorrelation, OLS, GWR.

\section{Introduction}

Gravitational field anomalies measured by GRACE (Gravity Recovery and Climate Experiment) satellites have yielded estimates of changes in the terrestrial water storage (TWS) across various temporal and spatial scales [1-9]. The TWS estimates integrate the effects of all processes that impact water storage and flux at the Earth's surface down to the deepest groundwater aquifer [2, 10-13]. These include anthropogenic activities (e.g., water storage in reservoirs, water withdrawal, and use, water diversion, land surface modification, population), biophysical processes (e.g. vegetation and land cover changes), and hydroclimatic processes (e.g. precipitation, groundwater storage, soil moisture, evapotranspiration), among others [2, 4, 10-12, 14-23]. Complex interactions among these processes determine the amount, timing, and variations in TWSA. Consequently, GRACE-derived 
TWS anomalies have been used in an expanding array of studies to investigate water scarcity [7], groundwater depletion [2, 10-13], lake storage variations [19, 21, 24, 25], snow and glacial mass changes [26, 27], as well as floods [28, 29] and droughts [15, 30-34]. These processes vary significantly over time and space, and the degree of variability increases as the study domain increases. Other studies have correlated interannual variability in GRACE anomalies to precipitation data [3], land surface model outputs [35-39], or explained how climate forcing, such as El Niño-Southern Oscillation (ENSO) and Indian Ocean Dipole (IOD) drive GRACE anomalies in various basins [4043].

To date, however, few studies have investigated how the factors that affect GRACE-TWS (e.g., precipitation, runoff, soil moisture, evapotranspiration) interact and combine over space and time to produce the mass variations that GRACE detects. Furthermore, it is reasonable to hypothesize that assorted sets of variables likely interrelate in different climatic settings to influence total water storage. That is, at one location or climatic zone, any single variable or combination of variables, may covary positively or negatively with TWS while, at another, the converse might apply. This paper builds upon the framework established by current studies to investigate an expanded array of hydrologic and anthropogenic processes and explicitly analyzes their relationship to TWS in different climatic zones in the Nile River Basin in Africa.

The Nile Basin is a hotspot for potential conflict over water resources owing to conflicting demands and rapid population growth [44-47]. Furthermore, the basin's physical environment is quite heterogeneous spatially, spanning Africa's most extensive mountain systems, largest marshlands, tropical rainforest, and desert [48]. The human geography of the basin is equally diverse; it includes areas with some of the highest population densities anywhere in Africa (e.g., the Nile delta and floodplain in Egypt), as well as extremely low-density areas in the Sahara and marshlands. These attributes make the Nile Basin uniquely suited for analyzing the effects of anthropogenic and physical processes on the spatiotemporal variability in total water storage.

To investigate these dynamics, we implement two geographically multiple regression (GMR) approaches, unweighted or ordinary least square (OLS) regression and geographically weighted regression (GWR). The OLS treats the variables equally across the study domains; while The GWR assigns a weight to each variable for each location proportionate to its contribution to TWS at that specific location, relative to all other variables [49-51]. The two models attempt to explain variations in TWS as a function of the intensity and interactions of trends in each of the independent variables in the model at different spatial domains. Using geospatial modeling, we analyze and map the spatial patterns in each independent variable and then explain the global (i.e., basin-wide), and local (spatially weighted) explanatory variables.

Knowledge concerning such processes and relationships has important scholarly and practical applications. From the perspective of research, it is useful for developing robust statistical models for reconstructing time series of proxy GRACE anomalies that predate the launch of the GRACE mission (April 2002), as well as filling the record gap between GRACE and GRACE Follow-On (GRACE-FO) mission. Additionally, significantly improves our understanding of the hydroclimatic, anthropogenic, and biophysical processes and dynamics that impact TWS occurrence and variability at the intra-basin scale. From an applied perspective, such information is critical for planning and resources management in areas undergoing rapid population change and environmental stresses. For example, it can be used to assess the risk that different activities and processes pose, individually or in different combinations, to total water resources availability and change.

The paper is organized as follows. Following this introduction, section 1.2 describes the study area; section 2 describes the data and methods employed; section 3 presents the results and discusses their implications; finally, section 4 summarizes the most important findings and conclusions. 


\subsection{Nile River Basin}

With a total flow length approximately $6,700 \mathrm{~km}$, the Nile is the longest river in the world. The river has two major tributaries; the White and Blue Niles. Other important tributaries include the Sobat and Bahr El-Jebel, which flow into the White Nile, and the Atbara River, which joins the Nile below the confluence of the White and Blue Niles (Figure 1). Together, these rivers drain a total basin area of 3.3 million square kilometers, or about 11 percent of Africa's total land mass. From south to north, the basin traverses five bioclimatic zones namely, tropical, subtropical, semiarid, arid and Mediterranean climate zone $[48,52,53]$. The headwaters of the Blue and Atbara rivers originate in the subtropical mountain bioclimatic zone of Ethiopia, while the tropical bioclimatic zone forms the Sobat and Bahr El-Jebel sub basins. Precipitation and surface runoff patterns vary significantly across the basin in response to this climatic heterogeneity. Precipitation declines from over $1000 \mathrm{~mm} / \mathrm{yr}$. in the tropical regions in the headwaters of the White Nile to less than $100 \mathrm{~mm} / \mathrm{yr}$. in the arid zone below the delta [54]. Actual evapotranspiration (ET) follows a similar pattern; it exceeds $1000 \mathrm{~mm} / \mathrm{yr}$. in the tropical and subtropical zones, but declines to less than $80 \mathrm{~mm} / \mathrm{yr}$. in the arid zone [48, 54, 55]. In contrast, the reference evapotranspiration (PET) grades in the opposite direction, increasing from $1,100 \mathrm{~mm} / \mathrm{yr}$ in the tropical and subtropical zones to over 3,000 mm/yr. in the semiarid and arid zones as land surface temperature rises [48,54-56]. This potentially leads to a relatively low runoff rates in the basin; the average water flow is about $0.98 \mathrm{~L} / \mathrm{s} / \mathrm{Km} 2$ [57-59]

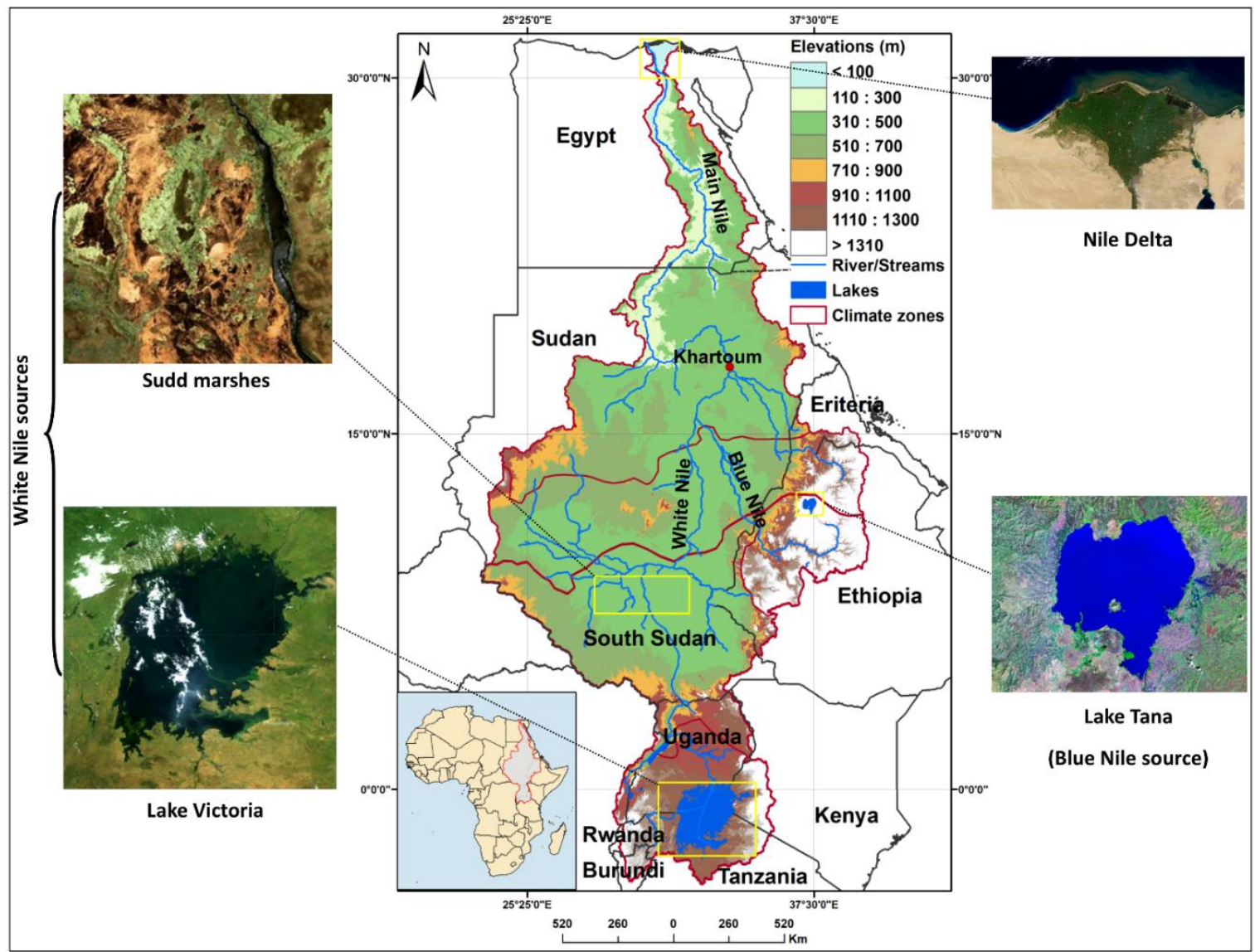

Figure 1. Physiographic map of the Nile River Basin (NRB), the inset map (source Landsat 7) indicates the main Nile systems include Blue Nile system (Lake Tana), White Nile system (Lake Victoria and Sudd marshes), and Main Nile (Nile Delta).

In terms of the human and political geography, the NRB comprises 11 countries with a total population of nearly 400 million (2012;[60]). The basin's population is projected to reach 800 million by 2050 [61]. The Nile basin is a water conflict hotspot because of the multiplicity of countries with competing demands and conflicting priorities that share the basin [62-64]. Rapid population growth 
and devastating historical droughts compel upstream (source) countries to exploit the Nile's water resources to support ambitious development plans. An example is the Grand Ethiopian Renaissance Dam (GRED) on the Blue Nile, which will be the largest hydroelectric power plant in Africa when it is completed. Yet, Egypt, a downstream country, depends on the Nile more directly and intensely than any other country depends on any single resource. Conflict theorists postulate that such high dependence on a single resource increases the likelihood that a country might risk conflict or event war to protect that resource $[65,66]$. At the same time, thus, to both upstream and downstream countries, the Nile is critical to survival, food security and development planning. Fortunately, the countries in the region and the international community are keenly aware of these risks. As result, the Nile basin today has arguably more treaties governing its use than any other international River Basin in the world [67]. In support of these treaties, numerous models and simulations of the basin's water resources continue to be developed and refined as knowledge of the water resources dynamics of the basin improves. This study is a contribution toward improved understanding of the TWS variability over space and time in the Nile Basin.

\section{Data and Methods}

Table 1. lists the sources and spatial resolutions of the datasets utilized in this study. Briefly, the data include: monthly GRACE TWS Mass Concentration block (mascons) anomalies for the period April 2002 to December 2016 processed by the Center for Space Research (CSR-M) at the University of Texas at Austin (UT, Austin; [68]). The CSR-M mascons, likewise other mascon products, (i.e., the Goddard Space Flight Center (GSFC) GSFC-M, and the NASA Jet Propulsion Laboratory (JPL) JPL$\mathrm{M})$, characterized by retaining reliable TWS signals over noise, and can be utilized directly in any hydrologic applications without preprocessing or the applications of scaling factor for signals restoration [69]. That is, no specific preferences to utilize the CSR-M solutions in this study over another mascons. Precipitation data acquired from the Global Precipitation Climatology Centre (GPCC), the GPCC gauge-corrected precipitation dataset from the Deutscher Wetterdienstt (DWD) [70, 71]; surface runoff (R), and groundwater data (GW) from the WaterGAP hydrological model outputs (WGHM; [72-74]). Actual (ET) and reference (PET) evapotranspiration estimates were obtained using the approach described by [75], the data are internally stored at the Hydrometeorology and Remote Sensing Laboratory ( $\underline{\mathrm{HyDROS}}$ ) server. Surface water (SW) data, and Soil Moisture (SM) estimates obtained from the Noah Global Land Surface Model (GLDAS) V2.1 output, which integrates soil moisture at four depths (0:10, 10:40, 40:100 and 100:200 cm below ground surface), as well as the canopy water content (CWC) [76]. The Normalized Difference Vegetation Index (NDVI) data obtained from the Goddard Earth Sciences Data and Information Services Center GES DISC. The NDVI data derived from the global monthly gridded Moderate Resolution Imaging Spectroradiometer (MODIS), MOD13C2, [77] collection-5. Finally, population density information was derived from the Gridded Population of the World version 4 (GPWv4) corrected population estimates provided by the Socioeconomic Data and Applications Center (SEDAC) [78]. These data are available at uneven temporal and spatial scales (see table 1). To project the data to common and consistent spatiotemporal scales; therefore, the non-parametric Theil-Sen slope trend was calculated on the original spatial resolution of each grid. Then a fixed sample grid to GRACE CSR-M product was used to sample the corresponding trend value at a fixed spatial resolution of 1.0-degree grid. The associated uncertainty in each variable was expressed using standard deviations of the residual component following standardized approaches $[7,39,69,79,80]$. 
Table 1. Summary information of dataset sources utilized in this research

\begin{tabular}{cccc}
\hline Category & Variable & Resolution & Data Source \\
\hline Water storage & TWS & $1.0^{\circ}$ & $\underline{\text { CSR-UT }}$ \\
Geophysical & $\mathrm{P}$ & $1.0^{\circ}$ & $\underline{\text { GPCC }}$ \\
& $\mathrm{R}$ & $0.5^{\circ}$ & $\underline{\text { WaterGAP }}$ \\
& $\mathrm{ET}$ & $0.25^{\circ}$ & $\underline{\text { HyDROS }}$ \\
& $\mathrm{SW}$ & $0.25^{\circ}$ & $\underline{\text { GLDAS-Noah }}$ \\
& $\mathrm{SM}$ & $0.25^{\circ}$ & $\underline{\text { GLDAS-Noah }}$ \\
& $\mathrm{GW}$ & $0.5^{\circ}$ & $\underline{\text { WaterGAP }}$ \\
Vegetation & PET & $0.25^{\circ}$ & $\underline{\underline{\text { HyDROS }}}$ \\
Anthropogenic & Pop. Den. & $0.5^{\circ}$ & $\underline{\text { NDVI }}$ \\
\hline
\end{tabular}

\subsection{Trend Analysis}

In general and subject to a number of qualifying assumptions, the relationship between a dependent variable e.g. TWSA, and several independent variables can be analyzed based on either the raw values of the process or on the dominant component characterizing the time series, such as trends, cycles, and seasonality [59, 81-85]. With specific respect to TWSA across Africa, previous research (e.g., $[7,16,18,19,24,25,35,38,86])$ showed that large parts of the continent are experiencing statistically significant declining TWSA trends. The studies further established that the trend component provides a robust means of investigating the relationship between TWSA and the driving hydrologic variables. In theory, the degree to which the trend component may explain temporal variability in a time series can be calculated according to [85] explicitly as;

$$
F_{T}=\operatorname{Max}\left(0,1-\frac{\operatorname{Var}(R)}{\operatorname{Var}(T+R)}\right)
$$

where, FT is the strength of the trend, $\operatorname{var}(R), \operatorname{var}(T+R)$, are the variances of the residual, trend and seasonality. The range of the ratios is between 0 and $1 ; 0$, signifying no contribution of the trend component to time series variability. Conversely, as $\operatorname{Var}(T+R)$ increases relatively to the numerator, FT asymptotically approaches 1, signifying increasing contribution of the trend component to time series variability. Figure 2 shows the general framework of the methodology.

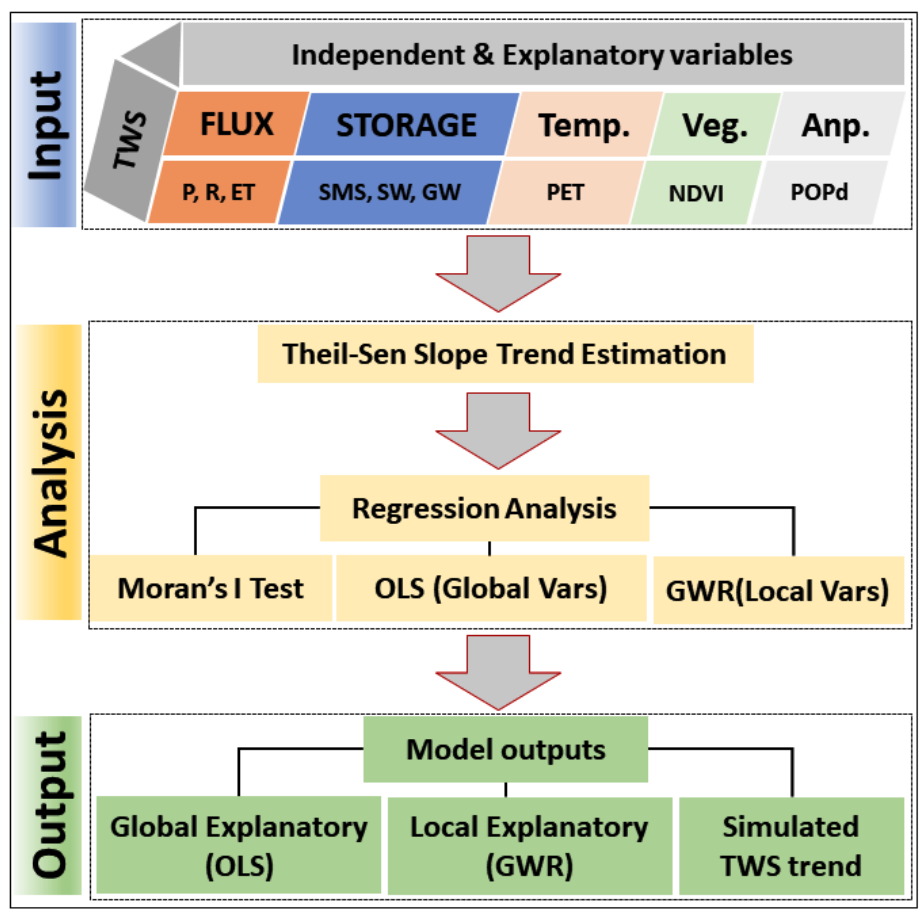


Figure 2. Graphical abstract shows the flow of data analysis.

The Theil-Sen slope in each variable (Xi) was estimated using the non-parametric Mann-Kendall (MK) trend test [87-89]. The significance of the trend was tested using the Sen's slope method. These methods are widely used for trend estimation, and justification for their use appears in numerous publications [38, 39, 90-92]. The Mann-Kendall statistic $(S)$ for a time series $x_{1}, x_{2}, \ldots, x_{n}$ is calculated as,

$$
\begin{gathered}
\qquad=\sum_{k=1}^{n-1} \sum_{i=k+1}^{n} \operatorname{sgn}\left(x_{i}-x_{k}\right) \\
\text { where } \operatorname{Sgn}\left(x_{1}-x_{2}\right)=\left\{\begin{array}{r}
+1,\left(x_{1}-x_{2}\right)>0 \\
0,\left(x_{1}-x_{2}\right)=0 \\
-1,\left(x_{1}-x_{2}\right)<0
\end{array}\right.
\end{gathered}
$$

The Mann-Kendall method tests the presence and significance of a trend but not its magnitude. Therefore, we applied Sen's slope estimator, $\left(Q_{i}\right)$, to determine the magnitude of trend in each $x_{i}$ with statistically significant trend. The test is calculated as,

$$
Q_{i}=\frac{x_{j}-x_{k}}{t_{j}-t_{k}}, i=1,2, \ldots \ldots N, j>k
$$

where $x_{j}$ and $x_{k}$ are as previously defined. The slope is measured at $n$ points in the time series, $N=n(n-1) / 2, Q_{i}$ is the median of these $N$ values. We accessed to the Sen's slope algorithm via the CARN.R-project, the spatialEco package, for spatial analysis and modeling utilities [93]. We calculated the trend variation on each variable applying this Theil-Sen's slope approach (Equation 4), (Figure 3) with the associated confidence intervals and uncertainties across the basin (not shown in the figure). 

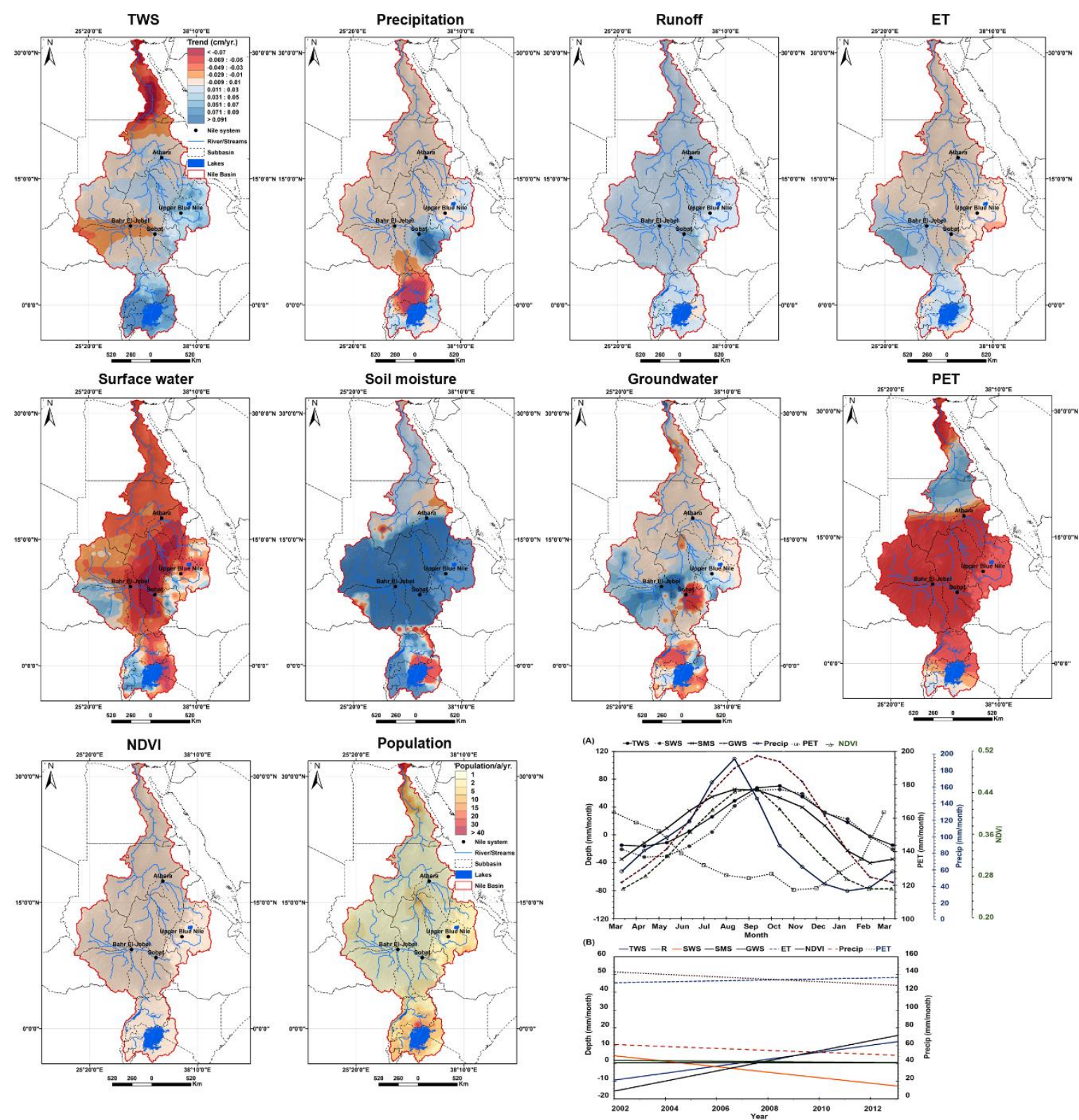

Figure 3. Spatial patterns of the Sen's slopes for the TWS and other variables across the NRB. Plots $(A \& B)$ show the seasonal and the trend pattern, respectively.

\subsection{Geographically Multiple Regression (GMR) Analysis}

Herein, we make use of the gridded trend outputs for dependent and explanatory variables in a geographically multiple regression (GMR) formulation to investigate spatiotemporal variability in TWSA as a function of variations in the relevant controlling processes. That is;

$$
y=\alpha+\beta_{t 1}\left(x_{t 1}\right)+\beta_{t 2}\left(x_{t 2}\right)+\beta_{t n}\left(x_{t n}\right)+\varepsilon
$$

where, $y$ is the independent variable (TWSA), $x_{t 1}, x_{t 2}, \ldots, x_{t n}$ are the explanatory variables, $\alpha$ is the model intercept, $\beta_{t}$ is the coefficient associated with each variable, and $\varepsilon$ is the residual $(y-\hat{y})$. For this analysis, the explanatory variables analyzed include, three (SM, SW, GW) represent storage processes while P, R, ET and PET are flux variables, NDVI and population density (pop den.) represents the vegetation and anthropogenic proxies.

The results of the Theil-Sen's slope test are noisy and spatially incoherent. Therefore, we utilized Moran's I index to identify clusters and spatial pattern of trends in each variable. Moran's I calculates the spatial autocorrelation among neighboring points distributed across a study domain [94, 95], i.e., 


$$
I=\frac{1}{\sigma^{2}} \frac{\sum_{i} \sum_{j}\left(x_{i}-\bar{x}\right)\left(x_{j}-\bar{x}\right)}{\sum_{i} \sum_{j} \omega_{i j}}
$$

where $x$ is trend value indexed by $i$ and $j$ locations; $\bar{x}$ is the mean of $x ; \sigma^{2}$ is the variance, and $\omega_{i j}$ is a matrix of spatial weights. For this analysis, the $\omega_{i j}$ 's were estimated following the method of [50]. Equation (6) produces normalized values of I, which are used to classify the degree of clustering, dispersion, or randomness in the study process. The process is classified as clustered/dispersed if Moran's I is positive/negative and statistically significant $(\mathrm{p}<0.05)$. Otherwise, the process is classified as random. Each identified cluster is summarized according to the original GRACE footprint of an area of $>3$-degree resolution.

To assess the effects of clustering on TWS variability spatially, we implemented both an unweighted OLS regression model, (Equation 2), as well as a geographically weighted regression (GWR) model (equation 7). The OLS calculates the basin-wide or global coefficients contributing to TWS variability using least square fitting approach. In essence, the contributions of all variables are deemed equal at all locations. The GWR is conceptually similar to OLS with the difference that the model assigns weights to each variable based on occurrence of clusters. That is, the relative contributions of the independent variables vary spatially. The GWR uses the values of neighboring pixels to estimate a location-specific relationship among variables i.e.,

$$
y_{i}=\alpha\left(p_{i}\right)+\beta_{1}\left(p_{1}\right)\left(x_{1}\right)+\beta_{2}\left(p_{2}\right)\left(x_{2}\right)+\beta_{n}\left(p_{n}\right)\left(x_{n}\right)+\varepsilon_{i}
$$

where, $p i$ is pixel location. The model established area with radius $(r)$ to calibrate the least squares regression fitting. The regression model centered at each $p$ is assigned a binary weight value between 1 and 0 , depending on whether it is contained within a cluster or not. That is, the weight $\omega_{i j}$ given to observation $j$ would be,

$$
\omega_{i j}= \begin{cases}1 & \text { if } d_{i j} \leq r, \\ 0 & \text { if } d_{i j}>r\end{cases}
$$

where, $d_{i j}$ is the distance between the location of observation $i$ and $j$. To assign representative weight values, the value of the weight decays according to Gaussian distance-decay-function i.e.,

$$
\omega_{i j}= \begin{cases}\left\{1-\left(d_{i j} / b\right)^{2}\right\}^{2} & \text { if } d_{i j} \leq r, \\ 0 & \text { if } d_{i j}>r\end{cases}
$$

where, $b$ is a nonnegative decay parameter describing the relationship between the weight and distance. Therefore, the results aren't displayed in binary format.

For both OLS and GWR, we investigated each model efficacy using standard goodness-of-fit diagnostics including Maximum Likelihood of variance (ML of Variance), unbiased variance, mean square srror (MSE), Classic Akaike information criterion (Classic AIC), Akaike information criterion corrected (AICc), Bayesian information criterion (BIC), minimum description length (MDL), cross validation (CV), correlation coefficient (R2), adjusted R2, (see, Tables 3 and 4).

\section{Results and Discussion}

Figure 3 shows plots of the spatial patterns of trends of different variables at the pixel level. A number of patterns are noteworthy from this figure. First, each variable shows a different and unique spatial trend pattern across the basin. Some variables, e.g. runoff and soil moisture, show predominantly positive trends while others, e.g. surface water and PET are predominantly negative. Second, some variables, e.g. precipitation and groundwater, show strong tendency to clustering while other, e.g. NDVI show little to no clustering. Third, because TWSA integrates the effects of interactions among all variables, it displays a spatial trend pattern that is distinct from any individual variable. To highlight the importance of the trend component, Table 2 summarizes the strength of trend in each variable calculated according to (Equation 1). Table 2 shows as well the result of Moran's clustering index for each variable across the Nile basin. For the Nile basin at large, TWSA has a 
positive increasing trend of $2.17 \mathrm{~mm}, \pm 0.128 \mathrm{~mm} / \mathrm{yr}$. The results compare favorably with those reported by e.g., [16], based on analysis of TWS trends for different sub-basins. The authors found positive GRACE trend ( $3.14 \mathrm{~mm}, \pm 0.27 \mathrm{~mm} / \mathrm{yr}$.) for the Blue Nile and Atbara sub basins. On the other hand, the authors reported negative GRACE trends ( $-3.72 \mathrm{~mm} \pm 0.27 \mathrm{~mm} / \mathrm{yr}$.; $99 \%$ confidence) for the Nubian sandstone aquifer.

Table 2. Diagnostic of trend component through strength analysis, Theil-Sen slope, confidence interval (CI), and Moran's I clustering.

\begin{tabular}{ccccc}
\hline Parameter & Strength & Theil- Sen & CI & Moran' I \\
\hline TWS & 0.63 & $\mathbf{2 . 1 7 ^ { * }}$ & \pm 0.128 & $\mathbf{0 . 8 4}^{*}$ \\
P & 0.18 & $-\mathbf{0 . 4 4}$ & \pm 0.112 & $\mathbf{0 . 9 1}^{*}$ \\
R & 0.08 & -0.44 & \pm 0.112 & $\mathbf{0 . 5 2}^{*}$ \\
ET & 0.30 & $\mathbf{0 . 6 0 ^ { * }}$ & \pm 0.052 & $\mathbf{0 . 9 2}^{*}$ \\
SW & 0.77 & $\mathbf{- 1 . 5 1 ^ { * }}$ & \pm 0.151 & $\mathbf{0 . 6 9 *}$ \\
SM & 0.81 & $\mathbf{2 . 6 7 ^ { * }}$ & \pm 0.136 & $\mathbf{1 . 0 7 ^ { * }}$ \\
GW & 0.61 & -0.06 & \pm 0.012 & $\mathbf{0 . 0 9}$ \\
PET & 0.47 & $-\mathbf{0 . 6 4}$ & \pm 0.044 & $\mathbf{0 . 0 7}$ \\
NDVI & 0.43 & 0.003 & \pm 0.000 & 0.00 \\
Pop. Den. & -------- & 1.49 & \pm 0.112 & $\mathbf{0 . 3 6}$ \\
\hline
\end{tabular}

Table 2 shows that the trends in ET, SWS, SMS, GWS, and PET, are statistically significant $(\mathrm{p}<0.0001)$ at the scale of the basin as whole. Two variables (ET, SMS) show positive trends of 0.60 $\mathrm{mm}, \pm 0.05 \mathrm{~mm} / \mathrm{yr}$. and $2.67 \mathrm{~mm} \pm 0.14 \mathrm{~mm} / \mathrm{yr}$. respectively. The positive ET trend likely reflects rising atmospheric temperature in the basin, approximate $2^{\circ} \mathrm{C}$ over the past 20 years [54]. On the other hand, the strong positive SM trend is less intuitive given negative precipitation and positive ET. The result suggests that the aggregated soil moisture storage over the entirety of the basin has increased during the study period. Conversely, SW and PET show statistically significant negative trends $(-1.51 \mathrm{~mm}$, $\pm 0.15 \mathrm{~mm} / \mathrm{yr} ;-0.64 \mathrm{~mm}, \pm 0.04 \mathrm{~mm} / \mathrm{yr}$.) respectively. Similar to ET, the negative trend in SW is obvious and likely related to higher atmospheric temperature. We theorize that the declining PET indicates that the basin on average has become more water limited thereby providing less opportunities for evapotranspiration despite the availability of energy. However, further studies are needed to establish definitive conclusions. The groundwater trend shows only mildly declining trend. In general, the storage processes (i.e. SW, SM and GW), explain a larger proportion of the trend in TWSA compared to flux processes (e.g. P, R, ET, PET). The larger contributions of the storage variables may reflect their relative magnitude, as well as the fact that two storage processes (SM and GW) occur continuously over time and everywhere in the basin whereas flux processes are more likely to be temporally episodic and spatially discontinuous.

Moran's index revealed statistically significant clustering $(\mathrm{p}<0.0001)$ in all variables, except NDVI. The lack of clusters in NDVI likely reflects the random distribution of vegetation and or similarities in the vegetation response to TWS variability across the Nile basin. Although all variables showed degrees of clustering, the locations of these clusters and therefore the spatial patterns are distinctive for each variable. This effect is easily inferred from Figure 3.

\subsection{GMR Outputs}

Prior to model development, multicollinearity among the independent variables was evaluated using Tolerance and VIF (Table 3). The results are satisfactory based on the criteria of tolerance $>0.20$ and VIF $<3.0$ [96]. Development of the final regression models was done in one of two ways. In the case of OLS, one regression model, consisting all of the five statistically relevant independent variables, was produced for the entire basin. The GWR, on the other hand, produced different model equations at each geographic location. For instance, five equations explained the conventional 
climatic subdivisions of the Nile Basin, and four others based on different sub-basins. The variables retained in the final OLS model include P, R, SW, SM, and Pop. Den. The OLS correlation coefficient (R2) value is low, R2 0.14, likely results from the cancellations in sign and magnitude due to differences in the direction and intensity of trends across the basin.

Table 3. Multicollinearity test and OLS model outputs; the OLS revealed five main global explanatory variables across the NRB include precipitation, runoff, surface water, soil moisture and population as indicated by p-values (highlighted).

\begin{tabular}{|c|c|c|c|c|c|c|c|}
\hline \multicolumn{4}{|c|}{ Multicollinearity test } & \multicolumn{4}{|c|}{ OLS } \\
\hline Parameter & R2 & Tolerance & VIF & Coef. $[\beta]$ & Std. Error & t-Statistic & P-value \\
\hline Intercept & ---- & ---- & ---- & 0.004 & 0.002 & 1.973 & $0.049^{*}$ \\
\hline TWS & 0.140 & 0.860 & 1.163 & ---- & ----- & ----- & ----- \\
\hline $\mathbf{P}$ & 0.200 & 0.800 & 1.251 & -0.160 & 0.058 & -2.733 & $0.006^{*}$ \\
\hline $\mathbf{R}$ & 0.144 & 0.856 & 1.168 & 3.913 & 1.122 & 3.487 & $0.001^{*}$ \\
\hline ET & 0.112 & 0.888 & 1.127 & 0.074 & 0.122 & 0.605 & 0.545 \\
\hline sWs & 0.258 & 0.742 & 1.347 & 0.162 & 0.044 & 3.702 & $0.001^{*}$ \\
\hline SMS & 0.258 & 0.821 & 1.218 & 0.029 & 0.004 & 6.541 & $0.000^{*}$ \\
\hline GWS & 0.179 & 0.472 & 2.117 & 0.005 & 0.005 & 0.978 & 0.329 \\
\hline PET & 0.547 & 0.453 & 2.208 & 0.005 & 0.006 & 0.903 & 0.367 \\
\hline NDVI & 0.031 & 0.969 & 1.032 & 0.934 & 0.736 & 1.270 & 0.205 \\
\hline POP & 0.187 & 0.813 & 1.230 & 0.002 & 0.004 & 5.060 & $0.000^{*}$ \\
\hline
\end{tabular}

Models evaluation using standardized residuals (Figure 4); the OLS model showed skewed standardized residuals (Figure 4A), where the model underestimates the TWS in the arid region (Figure 4B). The local R2 is homogenous with an average value of 0.14 (Figure 4C), which is low but statistically significant $(\mathrm{p}<0.001)$. This finding is not surprising. The model's assumption of equal contribution by all variables to the basin-wide TWS is clearly inconsistent with the results of Figure 3. On the contrary, the GWR model standardized residuals are randomly distributed produced (Figure 4D) with few outliers in the arid regions (Figure 4E). The GWR local R2 is inhomogeneous and varies across the basin (Figure 4F) with R2 coefficient of average $0.86(p<0.001)$. Significantly, the standardized residuals are much better behaved in the GWR model. Thus, the degree of explained variance in TWS improves as the regression model takes into account local differences in the strengths of each variables' contributions to the TWS variability across the basin. 

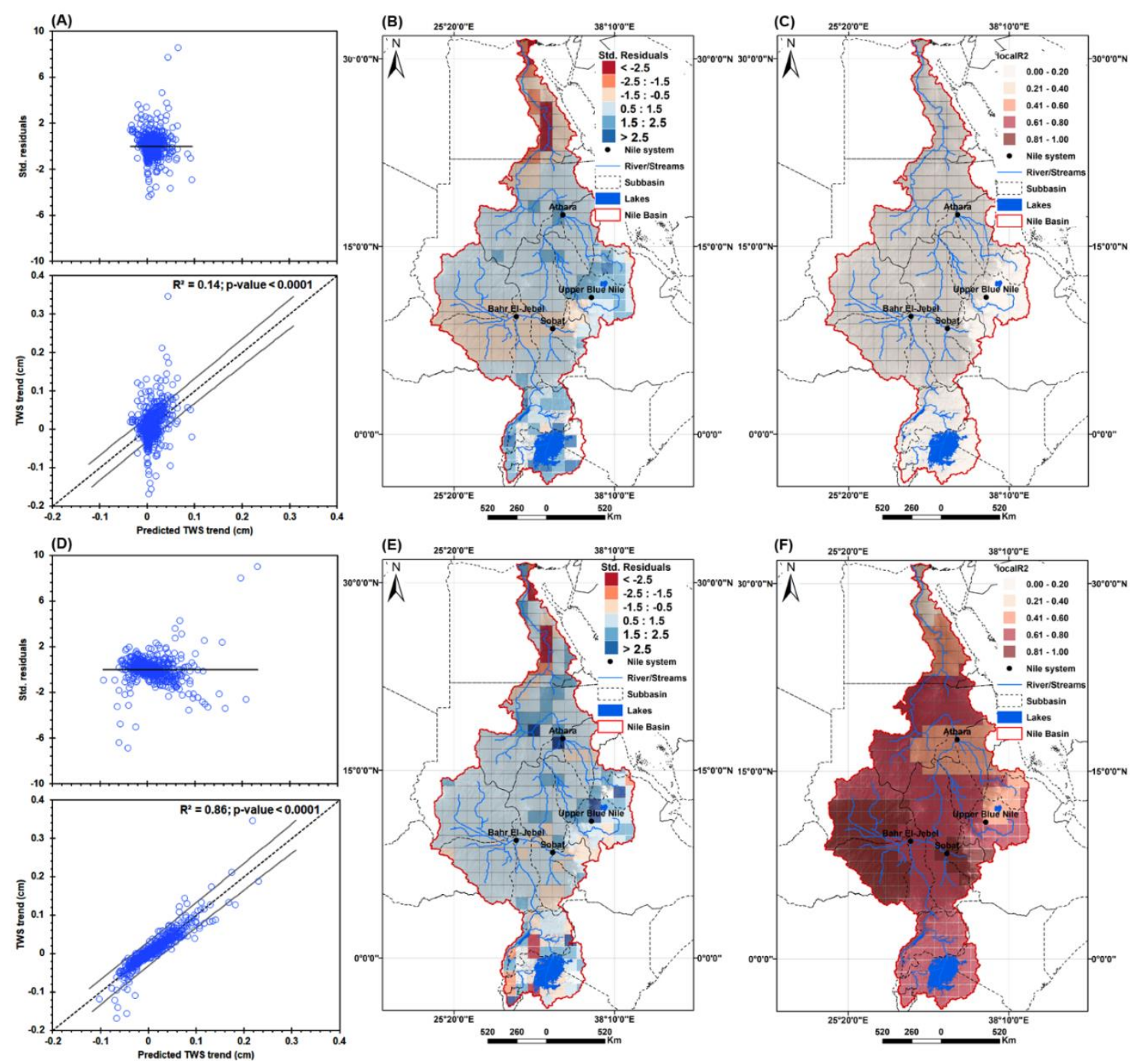

Figure 4. OLS and GWR model outputs include scatterplots of standard residuals and the correlation coefficient R2 (A, D), also the spatial distribution of the OLS and GWR standardized residuals (B, E) and local R2 (C, F) outputs.

To sum, the models' diagnostics for both OLS and GWR models, as is indicated in Table 4 showed the supremacy of the GWR model opposed to the OLS. Recall that the GWR weights the variables included in each model based on the result of the Moran's Index value.

Table 4. Diagnostic statistics of the OLS and GWR models; positive value of diff-Criterion (AICc, AIC, BIC/MDL) suggests no spatial variability in terms of model selection criteria.

\begin{tabular}{ccc}
\hline Diagnostic & OLS & GWR \\
\hline Residual sum of squares & 1.08 & 0.19 \\
ML of variance & 0.04 & 0.02 \\
Unbiased variance & 0.039 & 0.019 \\
MSE & 0.002 & 0.000 \\
Classic AIC & -2544.31 & -3449.43 \\
AICc & -2543.93 & -3344.35 \\
BIC/MDL & -2494.19 & -2687.22 \\
CV & 0.00 & 0.03 \\
R2 & 0.14 & 0.86 \\
Adjusted R2 & 0.14 & 0.86 \\
\hline
\end{tabular}


Figure 5 is a map of the locations (clusters) where each variable makes statistically significant contributions to TWA across the basin. The results show that precipitation is significantly correlated with TWS in the tropical region, Upper Blue Nile and trunk channel sub basin, Bahr El Ghazel, and the headwaters of the Atbara basin. Population density explains TWS in the headwaters and trunk channel sub-basins, but negatively elsewhere. Evapotranspiration makes the highest contribution in the arid and semiarid region as well as the central to western region of the basin dominated by wetland and the Sudd. Surface water contributes strongly and positively in the headwater regions of the White and Blue Nile. Thus, the results are consistent with the basins known hydroclimatic characteristics and behavior.
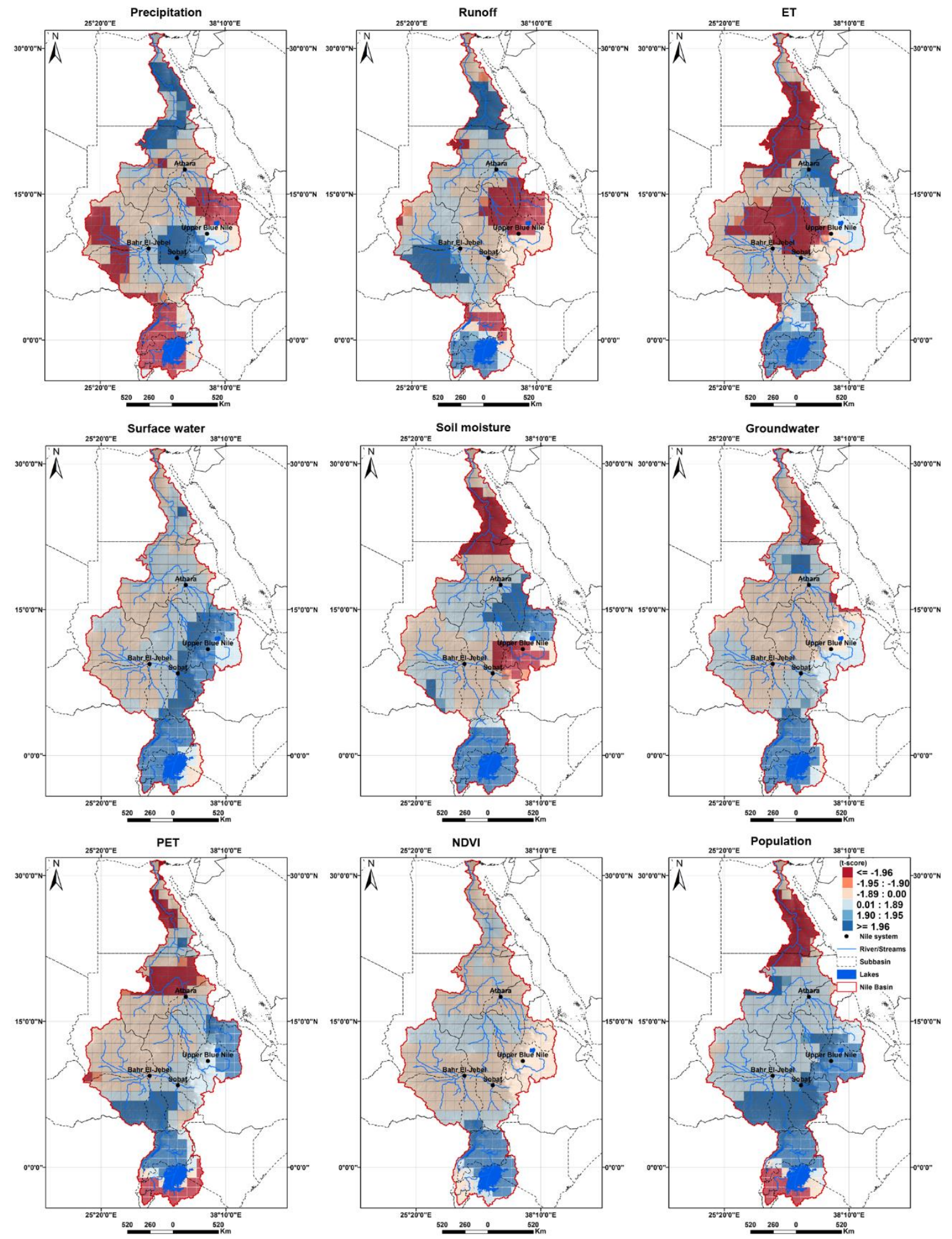
Figure 5. GWR output shows areas of a significant (two-sided) relationship between TWS trend with flux data (precipitation, runoff, ET); storage (surface water, soil moisture, and groundwater), and PET, NDVI and Pop. Den.; significant levels at alpha of 0.01 (1.90) or 90\% and 0.05 (1.95) or 95\%.

Taking above patterns into account, Figure 6 shows the variables retained in the GWR model equations by climate zone. Several observations are immediately obvious. As hypothesized, both the numbers and combination of variables contributing to the TWS are different for each climate zone. In the arid zone, the important variables include R, ET, SMS, PET, and Pop. Den. In the semiarid zone, TWS is driven primarily by ET and population density, whereas the model retained all variables in the tropical zone. Noteworthy, the population density is the only variable identified as statistically significant to TWS variability in every climate zone across the basin. The observation reflects the role of anthropogenic processes on water mass distributions.

\begin{tabular}{|c|c|c|c|c|c|c|c|c|c|c|}
\hline & Region & $\mathbf{P}$ & $\mathbf{R}$ & ET & SWS & SMS & GWS & PET & NDVI & Pop. \\
\hline \multirow{5}{*}{ 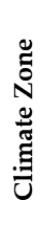 } & Arid & & & & & & & & & \\
\hline & Semiarid & & & & & & & & & \\
\hline & Subtropical-H & & & & & & & & & \\
\hline & Subtropical-M & & & & & & & & & \\
\hline & Tropical & & & & & & & & & \\
\hline \multirow{4}{*}{ 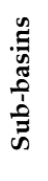 } & Main Nile & & & & & & & & & \\
\hline & Bahr El-Jabel & & & & & & & & & \\
\hline & BNB & & & & & & & & & \\
\hline & Lake Victoria & & & & & & & & & \\
\hline
\end{tabular}

Figure 6. GWR output shows the main explanatory variables summarized across five main climate zones and four main sub-basins is in the NRB. The results are significant at alpha $=0.05(1.96)$.

To evaluate the robustness of the GWR approach, we simulated the basin-wide TWS pattern using the GWR model output, the results with the GRACE TWS trends (Figure 7). The agreement is excellent $(\mathrm{R} 2>0.80)$.

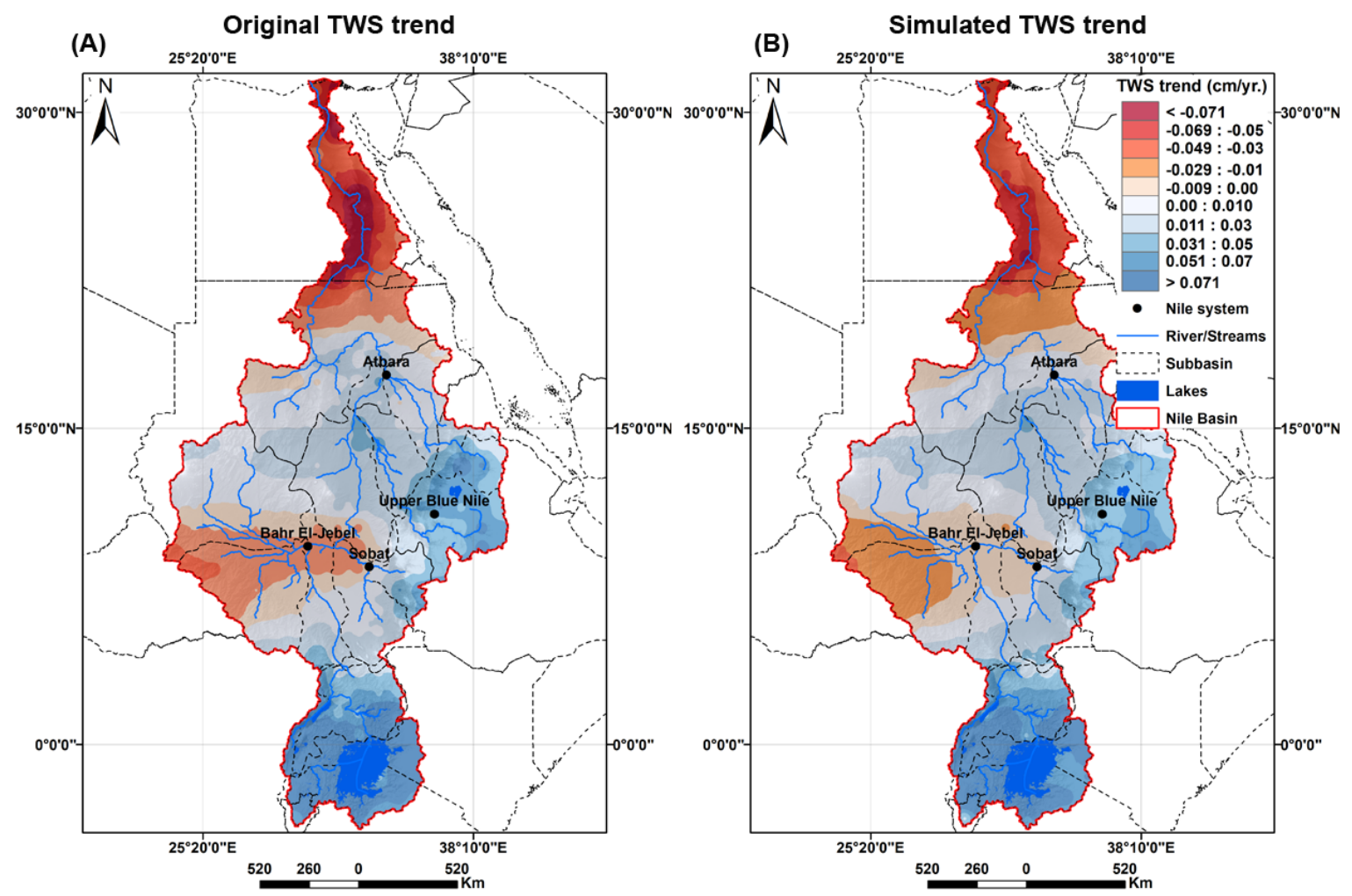


Figure 7. Original TWS Sen's slope (A), and simulated trend output using GWR model (B).

\section{Summary and Conclusions}

GRACE-derived total water storage anomalies have become an essential source of data in a growing array of hydrologic analysis and research. A common way in which the data have been analyzed is to correlate GRACE anomalies with various hydroclimatic phenomena, such as drought, floods and groundwater depletion, among numerous applications. Comparatively few studies have analyzed the question of how spatiotemporal variability among different basin processes interact to produce the mass distributions in water storage that GRACE detects. In this study, we attempted to fill that gap. To do so, we built regression models with TWSA as the dependent variable and eight anthropogenic and hydrologic processes as independent variables. The study adopted two important innovations. First, the regression modeling was carried out in terms of trends, rather than the raw values. Second, two types of regression models were developed. The first was an OLS, in which the basin is a single unit. Following standard evaluation and diagnostic analysis, the OLS model retained five variables, namely soil moisture, population, surface water, runoff, and precipitation. Collectively, the trends in these variables explained $14 \%$ of the trend in TWSA basin wide. This low explanatory power results, we believe, from the fact that the same variable produces opposing signs in different parts of the thereby cancelling out or nullifying its contribution.

The second approach, geographic weighted regression delineated clusters of trends in each variable and then assigned weights to those variables proportionate to the strength of the trend in different parts of the basin. This approach produced nine separate regression models, one for each of the five conventionally recognized climate zones in the Nile Basin and one for each sub-basin, all of which span several climatic zones. Each model comprised different variables, which were all weighted differentially, depending on the variability in strength of trend within the model domain. Using Moran's Index of variability, we delineated spatially coherent areas of trend clusters denoting areas experiencing increasing or decreasing trends in each independent variable. The results showed that precipitation trend is positively correlated with TWS across the Equatorial Lake, Sobat, and Upper Blue Nile in the east, the Bahr El Jebel basin in the west and across the Main Nile in the North. Evapotranspiration is positively correlated with TWS trend in the Equatorial Lake area, North Sobat basin, Atbara basin and upper and lower Main Nile basin. Surface water trend is an important contributor to TWS trends across the Southern and Eastern portion of the NRB, where major surface water reservoirs are abundant e.g. Lake Victoria, Lake Albert, Lake Koga and Lake Tana in the Blue Nile Basin. Soil moisture trend explained the TWS trends across the equatorial Lake areas, Sobat, Upper Blue Nile and Main Nile in the source areas in the north. These zones are characterized by the presence of major natural and artificial water reservoir in the basin. TWSA trend is associated with groundwater trend in the equatorial Lake zone and west area of the Red sea, crystalline rocks in the north of the basin. Finally, the trend in population density was statistically important, especially in the highly populated areas across the NRB including Equatorial Lake, Blue Nile Basin and the Main Nile in the north.

By explicitly accounting for the spatial variability in trends in this manner, the R2 values improved significantly, ranging between 0.40 and 0.89 with an average of $86 \%$. The results have potential applications in statistical modeling and analysis especially related to TWS reconstruction and gap filling. The result of the GWR results underscore the importance of accounting for differences in the contribution that variables makes toward TWSA in different parts of the basin. Because the clusters were ultimately used to explain GRACE derived TWSA, we ensured that the area of each cluster was at least 200,000 km2, the size deemed essential for robustly detecting the GRACE footprint.

Author Contributions: Conceptualization, E. Hasan and A. Tarhule; methodology, E. Hasan; Validation, E. Hasan; formal analysis, E. Hasan and A. Tarhule; writing-review and editing, A. Tarhule; supervision and funding acquisition, A. Tarhule. 
Funding: This research was funded by the Binghamton University Provost's office.

Acknowledgments: The authors thank the Provost's office at the State University of New York (SUNY) at Binghamton for providing research funds to this study. Thanks also go to the Advanced Radar Research Center and the Hydrometeorology and Remote Sensing Laboratory (HyDROS) at OU for providing the research facilities, workspace, and equipment to accomplish this research. We also wish to thank the providers of some important remote sensing and reanalysis datasets used in this research: The Center for Space Research (CSR) at the University of Texas, Austin, NASA Goddard Earth Science Data and Information Service Centers, WaterGAP hydrologic model, HyDROS group, and SEDAC.

Conflicts of Interest: The authors also would declare that there is no conflict of interest.

\section{References}

1. Tapley, B.D., et al., GRACE Measurements of Mass Variability in the Earth System. Science, 2004. 305(5683): p. 503.

2. Rodell, M., et al., Estimating groundwater storage changes in the Mississippi River basin (USA) using GRACE. Hydrogeology Journal, 2006. 15(1): p. 159-166.

3. Swenson, S. and J. Wahr, Estimating Large-Scale Precipitation Minus Evapotranspiration from GRACE Satellite Gravity Measurements. Journal of Hydrometeorology, 2006. 7: p. 252-270.

4. Longuevergne, L., et al., GRACE water storage estimates for the Middle East and other regions with significant reservoir and lake storage. Hydrology and Earth System Sciences, 2013. 17(12): p. 4817-4830.

5. Long, D., L. Longuevergne, and B.R. Scanlon, Global analysis of approaches for deriving total water storage changes from GRACE satellites. Water Resources Research, 2015. 51(4): p. 2574-2594.

6. Solander, K.C., et al., GRACE satellite observations reveal the severity of recent water over-consumption in the United States. Sci Rep, 2017. 7(1): p. 8723.

7. Hasan, E., et al., Assessment of Physical Water Scarcity in Africa Using GRACE and TRMM Satellite Data. Remote Sensing, 2019. 11(8).

8. Tapley, B.D., et al., Contributions of GRACE to understanding climate change. Nature Climate Change, 2019. 9(5): p. 358-369.

9. Hasan, E. and A. Tarhule, We use satellites to measure water scarcity. The Conversation, 2019.

10. Strassberg, G., B.R. Scanlon, and M. Rodell, Comparison of seasonal terrestrial water storage variations from GRACE with groundwater-level measurements from the High Plains Aquifer (USA). Geophysical Research Letters, 2007. 34(14)

11. Swenson, S., et al., Estimating profile soil moisture and groundwater variations using GRACE and Oklahoma Mesonet soil moisture data. Water Resources Research, 2008. 44(1): p. 1-12.

12. Strassberg, G., B.R. Scanlon, and D. Chambers, Evaluation of groundwater storage monitoring with the GRACE satellite: Case study of the High Plains aquifer, central United States. Water Resources Research, 2009. 45(5): p. n/a-n/a.

13. Syed, T.H., J.S. Famiglietti, and D.P. Chambers, GRACE-Based Estimates of Terrestrial Freshwater Discharge from Basin to Continental Scales. Journal of Hydrometeorology, 2009. 10(1): p. 22-40.

14. Bonsor, H.C., et al., Interpretation of GRACE data of the Nile Basin using a groundwater recharge model. Hydrology and Earth System Sciences Discussions, 2010. 7(4): p. 4501-4533.

15. Long, D., et al., GRACE satellite monitoring of large depletion in water storage in response to the 2011 drought in Texas. Geophysical Research Letters, 2013. 40(13): p. 3395-3401.

16. Ahmed, M., et al., The use of GRACE data to monitor natural and anthropogenic induced variations in water availability across Africa. Earth-Science Reviews, 2014. 136: p. 289-300. 
17. A, G., et al., Impact of changes in GRACE derived terrestrial water storage on vegetation growth in Eurasia. Environmental Research Letters, 2015. 10(12).

18. Hasan, E., et al., Potential Water Availability Index (PWAI): A New Water Vulnerability Index for Africa Based on GRACE Data. AGU Fall Meeting Abstracts, 2016. 41.

19. Hassan, A. and S. Jin, Water storage changes and balances in Africa observed by GRACE and hydrologic models. Geodesy and Geodynamics, 2016. 7(1): p. 39-49.

20. Felfelani, F., et al., Natural and human-induced terrestrial water storage change: A global analysis using hydrological models and GRACE. Journal of Hydrology, 2017. 553: p. 105-118.

21. Hasan, E., et al., Assessing Lake Level Variability and Water Availability in Lake Tana, Ethiopia using a Groundwater Flow Model and GRACE Satellite Data, in AGU Fall Meeting. 2017: New Orleans 11-15 Dec. 2017.

22. Mohamed, A., et al., Aquifer recharge, depletion, and connectivity: Inferences from GRACE, land surface models, and geochemical and geophysical data. GSA Bulletin, 2017. 129(5-6): p. 534-546.

23. Wan, W., et al., Editorial for Special Issue "Remote Sensing Water Cycle: Theory, Sensors, Data, and Applications". Remote Sensing, 2019. 11(10).

24. Swenson, S. and J. Wahr, Monitoring the water balance of Lake Victoria, East Africa, from space. Journal of Hydrology, 2009. 370(1-4): p. 163-176.

25. Moore, P. and S.D.P. Williams, Integration of altimetric lake levels and GRACE gravimetry over Africa: Inferences for terrestrial water storage change 2003-2011. Water Resources Research, 2014. 50(12): p. 96969720.

26. Velicogna, I., T.C. Sutterley, and M.R. van den Broeke, Regional acceleration in ice mass loss from Greenland and Antarctica using GRACE time-variable gravity data. Geophysical Research Letters, 2014. 41(22): p. 8130-8137.

27. Sutterley, T.C., et al., Evaluating Greenland glacial isostatic adjustment corrections using GRACE, altimetry and surface mass balance data. Environmental Research Letters, 2014. 9(1).

28. Reager, J., et al., Assimilation of GRACE Terrestrial Water Storage Observations into a Land Surface Model for the Assessment of Regional Flood Potential. Remote Sensing, 2015. 7(11): p. 14663-14679.

29. Reager, J.T., B.F. Thomas, and J.S. Famiglietti, River basin flood potential inferred using GRACE gravity observations at several months lead time. Nature Geoscience, 2014. 7(8): p. 588-592.

30. Cao, Y., Z. Nan, and G. Cheng, GRACE Gravity Satellite Observations of Terrestrial Water Storage Changes for Drought Characterization in the Arid Land of Northwestern China. Remote Sensing, 2015. 7(1): p. 10211047.

31. Long, D., et al., Drought and flood monitoring for a large karst plateau in Southwest China using extended GRACE data. Remote Sensing of Environment, 2014. 155: p. 145-160.

32. Ndehedehe, C.E., et al., Spatio-temporal variability of droughts and terrestrial water storage over Lake Chad Basin using independent component analysis. Journal of Hydrology, 2016. 540: p. 106-128.

33. Nie, N., et al., A Global Hydrological Drought Index Dataset Based on Gravity Recovery and Climate Experiment (GRACE) Data. Water Resources Management, 2017. 32(4): p. 1275-1290.

34. Sun, Z., et al., Drought evaluation using the GRACE terrestrial water storage deficit over the Yangtze River Basin, China. Sci Total Environ, 2018. 634: p. 727-738.

35. Ahmed, M., et al., Assessing and Improving Land Surface Model Outputs Over Africa Using GRACE, Field, and Remote Sensing Data. Surveys in Geophysics, 2016. 37(3): p. 529-556. 
36. Döll, P., et al., Seasonal Water Storage Variations as Impacted by Water Abstractions: Comparing the Output of a Global Hydrological Model with GRACE and GPS Observations. Surveys in Geophysics, 2014. 35(6): p. 1311-1331.

37. Scanlon, B.R., et al., Global models underestimate large decadal declining and rising water storage trends relative to GRACE satellite data. Proc Natl Acad Sci U S A, 2018. 115(6): p. E1080-E1089.

38. Hasan, E., et al., Hydroclimatic Variability in Africa's Transboundary River Basin Using +50 Years of Extended Terrestrial Water Storage. Earth and Space Science Open Archive, 2019.

39. Hasan, E., et al., +50 Years of Terrestrial Hydroclimatic Variability in Africa's Transboundary Waters. Sci Rep, 2019. 9(1): p. 12327.

40. Awange, J.L., et al., Water storage changes and climate variability within the Nile Basin between 2002 and 2011. Advances in Water Resources, 2014. 73: p. 1-15.

41. Awange, J.L., et al., Exploring hydro-meteorological drought patterns over the Greater Horn of Africa (19792014) using remote sensing and reanalysis products. Advances in Water Resources, 2016. 94: p. 45-59.

42. Khaki, M., et al., Understanding the association between climate variability and the Nile's water level fluctuations and water storage changes during 1992-2016. Sci Total Environ, 2018. 645: p. 1509-1521.

43. Shamsudduha, M., et al., Recent changes in terrestrial water storage in the Upper Nile Basin: an evaluation of commonly used gridded GRACE products. Hydrology and Earth System Sciences, 2017. 21(9): p. 4533-4549.

44. Awulachew, S.B., Vladimir Smakhtin, and D.M.a.D. Peden, The Nile River Basin Water, Agriculture, Governance and Livelihoods. 2012, New York, NY 10017: Routledge.

45. Jung, H.C., et al., Upper Blue Nile basin water budget from a multimodel perspective. Journal of Hydrology, 2017. 555: p. 535-546.

46. NBI, State of River Nile Basin 2012. Nile Basin Initiative (NBI), Entebbe. 2012.

47. Hasan, E., S.I. Khan, and Y. Hong, Investigation of potential sea level rise impact on the Nile Delta, Egypt using digital elevation models. Environ Monit Assess, 2015. 187(10): p. 649.

48. Collins, R., The Nile. 2002: Yale University Press/ New Haven and London.

49. Fotheringham, A., C. Brunsdon, and M. Charlton, Geographically Weighted Regression: The Analysis of Spatially Varying Relationships. 2002: Wiley.

50. Nakaya, T., Local spatial interaction modelling based on the geographically weighted regression approach. GeoJournal, 2001. 53(4): p. 347-358.

51. Shrestha, P.M., Comparison of Ordinary Least Square Regression, Spatial Autoregression, and Geographically Weighted Regression for Modeling Forest Structural Attributes Using a Geographical Information System (GIS)/Remote Sensing (RS) Approach in Geography. 2006, Calgary, Alberta http://people.ucalgary.ca/ mcdermid/Docs/Theses/Shrestha 2006.pdf.

52. Abtew, W. and A.M. Melesse, The Nile River Basin, in Nile River Basin. 2014. p. 7-21.

53. Shahin, M., Hydrology of the Nile Basin. 1985, New York: Elsevier Science Publishing Company Inc.

54. Camberlin, P., Nile Basin Climates, in The Nile : Origin, Environments, Limnology and Human Use, H.J. Dumont, Editor. 2009, Springer, Monographiae Biologicae. p. 307-333.

55. Conway, D., From headwater tributaries to international river: Observing and adapting to climate variability and change in the Nile basin. Global Environmental Change, 2005. 15(2): p. 99-114.

56. Hasan, E., et al., Runoff sensitivity to climate change in the Nile River Basin. Journal of Hydrology, 2018. 561: p. 312-321.

57. Moges, S.A. and M. Gebremichael, Climate Change Impacts and Development-Based Adaptation Pathway to the Nile River Basin. . River Basin. 2014: Springer International Publishing Switzerland. 
58. Senay, G.B., et al., Understanding the hydrologic sources and sinks in the Nile Basin using multisource climate and remote sensing data sets. Water Resources Research, 2014. 50(11): p. 8625-8650.

59. Hasan, E., Geospatial Modeling of Surface Water Trends Using Time Series and Image Observation Analysis, in Civil Engineering and Environmental Science. 2017, Universityof Oklahoma: ShareOK.

60. Oestigaard, T., Water Scarcity and Food Security along the Nile Politics, population increase and climate change. 2012, Uppsala: Nordiska Afrikainstitutet.

61. Haub, C. and T. Kaneda, 2013 World Population Data Sheet - Population Reference Bureau. 2019, Population Reference Bureau (PRB).

62. Gleick, P.H., The vulnerability of runoff in the Nile basin to climatic changes. The Environmental Professional, 1991. 13: p. 66-73.

63. Gleick, P.H., Water, War E Peace in the Middle East. Environment: Science and Policy for Sustainable Development, 1994. 36(3): p. 6-42.

64. Schwartz, D. and A. Singh, Environmental conditions, resources and conflicts. An introductory overview and data collection. 1999.

65. Ibrahim, A.M., The Nile Basin Cooperative Framework Agreement: The Beginning of the End of Egyptian Hydro-Political Hegemony. Missouri Environmental Law and Policy Review (MELPR), 2011. 18(2).

66. Martens, A.K., Impacts of Global Change on the Nile Basin Options for Hydropolitical Reform in Egypt and Ethiopia. IFPRI Discussion Paper 01052, 2011.

67. Wolf, A.T., Shira B. Yoffe, and M. Giordano, International waters: identifying basins at risk. Water Policy, 2003. 5: p. 29-60.

68. Save, H., S. Bettadpur, and B.D. Tapley, High-resolution CSR GRACE RL05 mascons. Journal of Geophysical Research: Solid Earth, 2016. 121(10): p. 7547-7569.

69. Scanlon, B.R., et al., Global evaluation of new GRACE mascon products for hydrologic applications. Water Resources Research, 2016. 52(12): p. 9412-9429.

70. Schneider, U., et al., Global Precipitation Analysis Products of the GPCC. 2011: Deutscher Wetterdienst, Offenbach a. M., Germany.

71. Schneider, U., et al., Evaluating the Hydrological Cycle over Land Using the Newly-Corrected Precipitation Climatology from the Global Precipitation Climatology Centre (GPCC). Atmosphere, 2017. 8(3).

72. Döll, P., et al., Global-scale assessment of groundwater depletion and related groundwater abstractions: Combining hydrological modeling with information from well observations and GRACE satellites. Water Resources Research, 2014. 50(7): p. 5698-5720.

73. Müller Schmied, H., et al., Variations of global and continental water balance components as impacted by climate forcing uncertainty and human water use. Hydrology and Earth System Sciences, 2016. 20(7): p. 2877-2898.

74. Müller Schmied, H., et al., Sensitivity of simulated global-scale freshwater fluxes and storages to input data, hydrological model structure, human water use and calibration. Hydrology and Earth System Sciences, 2014. 18(9): p. 3511-3538.

75. Zhang, K., et al., A continuous satellite-derived global record of land surface evapotranspiration from 1983 to 2006. Water Resources Research, 2010. 46(9): p. n/a-n/a.

76. Rui, H. and H. Beaudoing, README Document for NASA GLDAS Version 2 Data Products. 2019: Greenbelt, Maryland.

77. Huete, A., et al., Overview of the radiometric and biophysical performance of the MODIS vegetation indices. Remote Sensing of Environment, 2002. 83: p. 195-213. 
78. Center for International Earth Science Information Network, C.C.U., Gridded Population of the World, Version 4 (GPWv4): Basic Demographic Characteristics, Revision 10. 2017, NASA Socioeconomic Data and Applications Center (SEDAC): Palisades, NY.

79. Sultan, M., et al., Assessment of age, origin, and sustainability of fossil aquifers: A geochemical and remote sensing-based approach. Journal of Hydrology, 2019. 576: p. 325-341.

80. Tiwari, V.M., J. Wahr, and S. Swenson, Dwindling groundwater resources in northern India, from satellite gravity observations. Geophysical Research Letters, 2009. 36(18).

81. Adhikari, R. and R.K. Agrawal, An Introductory Study on Time Series Modeling and Forecasting. 2013, Germany, 2013. arXiv:1302.6613: LAP Lambert Academic Publishing.

82. Forkel, M., et al., Trend Change Detection in NDVI Time Series: Effects of Inter-Annual Variability and Methodology. Remote Sensing, 2013. 5(5): p. 2113-2144.

83. Gentle, J.E., Finding Patterns in Time Series, in R_TimeSeriesPatterns. 2017.

84. Wang, X., K. Smith, and R. Hyndman, Characteristic-Based Clustering for Time Series Data. Data Mining and Knowledge Discovery, 2006. 13(3): p. 335-364.

85. Hyndman, R.J. and G. Athanasopoulos, Forecasting: Principles and Practice. 2nd ed. 2018, OTexts.com/fpp2. Accessed on 05/1/2019: OTexts: Melbourne, Australia.

86. Forootan, E., et al., Multivariate Prediction of Total Water Storage Changes Over West Africa from MultiSatellite Data. Surveys in Geophysics, 2014. 35(4): p. 913-940.

87. Hamed, K.H. and A. Ramachandra Rao, A modified Mann-Kendall trend test for autocorrelated data. Journal of Hydrology, 1998. 204(1): p. 182-196.

88. Mann, H.B., Nonparametric tests against trend. Econometrica, 1945. 13: p. 245-259.

89. Pohlert, T., Non-Parametric Trend Tests and Change-Point Detection. 2018, R-CRAN.

90. Nikzad Tehrani, E., H. Sahour, and M.J. Booij, Trend analysis of hydro-climatic variables in the north of Iran. Theoretical and Applied Climatology, 2018. 136(1-2): p. 85-97.

91. Onyutha, C., et al., Analyses of rainfall trends in the Nile River Basin. Journal of Hydro-environment Research, 2016. 13: p. 36-51.

92. Sa'adi, Z., et al., Trends analysis of rainfall and rainfall extremes in Sarawak, Malaysia using modified MannKendall test. Meteorology and Atmospheric Physics, 2017. 131(3): p. 263-277.

93. Evans, J.S. and K. Ram, spatialEco: Spatial Analysis and Modelling Utilities. 2018.

94. Chen, Y., New approaches for calculating Moran's index of spatial autocorrelation. PLoS One, 2013. 8(7): p. e68336.

95. Shen, C., C. Li, and Y. Si, Spatio-temporal autocorrelation measures for nonstationary series: A new temporally detrended spatio-temporal Moran's index. Physics Letters A, 2016. 380(1-2): p. 106-116.

96. Wheeler, D. and M. Tiefelsdorf, Multicollinearity and correlation among local regression coefficients in geographically weighted regression. Journal of Geographical Systems, 2005. 7: p. 161-187. 